\title{
Adjustment of the natural ocean carbon cycle to negative emission rates
}

\author{
M. Vichi • A. Navarra • P. G. Fogli
}

Received: 28 April 2012 / Accepted: 23 December 2012 / Published online: 26 February 2013

(C) The Author(s) 2013. This article is published with open access at Springerlink.com

\begin{abstract}
Carbon dioxide removal (CDR) is the only geoengineering technique that allows negative emissions and the reduction of anthropogenic carbon in the atmosphere. Since the time scales of the global carbon cycle are largely driven by the exchanges with the natural oceanic stocks, the implementation of CDR actions is anticipated to create outgassing from the ocean that may reduce their efficiency. The adjustment of the natural carbon cycle to CDR was studied with a numerical Earth System Model, focusing on the oceanic component and considering two idealized families of CDR policies, one based on a target atmospheric concentration and one based on planned negative emissions. Results show that both actions are anticipated to release the anthropogenic carbon stored in the surface ocean, effectively increasing the required removal effort. The additional negative emissions are expected to be lower when the CDR policy is driven by planned removal rates without prescribing a target atmospheric $\mathrm{CO}_{2}$ concentration.
\end{abstract}

\section{Introduction}

The increase of atmospheric carbon content in the 20th century is unprecedented in climatic records from the past million years (e.g. Etkin 2010), and the impacts on the major climate system components are more and more evident (Trenberth et al. 2007). The present atmospheric $\mathrm{CO}_{2}$ concentration is the result of the dynamical

This article is part of a special issue on "Carbon Dioxide Removal from the Atmosphere: Complementary Insights from Science and Modeling” edited by Massimo Tavoni, Robert Socolow, and Carlo Carraro.

M. Vichi $(\varangle)$. A. Navarra · P. G. Fogli

Centro Euro-Mediterraneo sui cambiamenti Climatici (CMCC),

Viale Aldo Moro 44, 40127 Bologna, Italy

e-mail: marcello.vichi@bo.ingv.it

M. Vichi · A. Navarra

Istituto Nazionale di Geofisica e Vulcanologia (INGV), Bologna, Italy 
equilibrium between the anthropogenic emissions from fossil fuels (Boden et al. 2011), and natural sinks from terrestrial and oceanic components (Falkowski et al. 2000). The recent reconstructions of the global carbon balance (Friedlingstein et al. 2010) indicate a persistence of the fossil fuel emission rates, even if modulated by economical conditions. As a mitigation measure, the removal of excess atmospheric $\mathrm{CO}_{2}$ may become an option together with emission reductions, especially because the emission cut-off is still considered insufficient to mitigate the observed climate changes (e.g. Matthews et al. 2009; Solomon et al. 2009). Deliberate carbon dioxide removal (CDR) or air capture is the only geoengineering technique that may allow negative emissions (Keith 2009), although the current feasibility of CDR techniques are uncertain and the economical burden is yet to be determined. Field experiments at global scale are still difficult and probably unwise and so numerical simulations are the method of choice (Navarra et al. 2010) to investigate and possibly quantify the effect of CDR.

Notwithstanding the thermal inertia of the physical climate system, model results indicate that the restoration of preceding atmospheric compositions is indeed a plausible target, as the natural sinks - especially the ocean-are anticipated to respond to mitigation actions on decadal time scales. For instance, a multi-model analysis (Johns et al. 2011; Vichi et al. 2011) has shown that a 450 ppmv stabilization by the end of this century is likely to restore the same values of the $\mathrm{CO}_{2}$ air-sea fluxes as the ones that the models simulate in the '60s.

According to measurements and model results, about $2 / 3$ of the released anthropogenic carbon since the industrial era have been absorbed by natural sinks (Le Quéré et al. 2009). The question is thus what would happen to the carbon cycle if the atmospheric concentration is deliberately restored to a target value. Given the dynamical gas-phase equilibrium, the oceanic component is anticipated to release the portion of anthropogenic carbon accumulated since the pre-industrial period (see Gruber et al. 2009, for an overview). This ocean outgassing counteracts the planned removal effort, while the role of the terrestrial sink is more difficult to evaluate given the fact that the land sink is not directly known. Cao and Caldeira (2010) used an Earth System Model (ESM) of intermediate complexity to study the long term adjustment of the carbon cycle to an idealized one-time instantaneous CDR to preindustrial concentrations occurring at year 2050, using the IPCC SRES A2 emission scenario as baseline. The usage of a more simplified ESM allowed to perform longterm simulations, as the study addressed the temperature changes and carbon flux adjustment between the climate components up to year 2400. In this paper, we use an ocean-atmosphere carbon cycle model to investigate the adjustment of the ocean to idealized and more realistic CDR actions starting from a permanent current climate simulation. This central set of experiments is further complemented with the inclusion of the land carbon cycle and transient/scenario simulations, in order to extrapolate the results to more realistic conditions of the Earth climate system.

\section{Methods}

\subsection{Model description}

The CMCC Carbon Earth System Model (CMCC-CESM) consists of an atmosphereocean-sea ice physical core coupled to models resolving carbon cycle dynamics on land and ocean using the SILVA land surface model (Alessandri 2006), and the 
PELAGOS model for ocean biogeochemistry (Vichi et al. 2007; Vichi and Masina 2009). The technical features of the ESM are fully described in Fogli et al. (2009) and Vichi et al. (2011). This model has been used extensively, for the simulation of the carbon cycle (Vichi et al. 2011), for simulations of climate variability (Gualdi et al. 2008) and for seasonal forecasts (Alessandri et al. 2010). The carbon cycle components on land and in the ocean are capable to simulate the exchange of carbon in different biological forms by means of a functional group approach. The PELAGOS model (PELAgic biogeochemistry for Global Ocean Simulations) consists of the global ocean version of the Biogeochemical Flux Model (BFM, http://bfm.cmcc.it), with several planktonic groups, multiple nutrient limitations and a complete representation of inorganic ed organic carbon cycling in the marine environment (Vichi et al. 2007). The SILVA (Surface Interactive Land VegetAtion) model also includes the biophysical interactions with momentum, heat and water flux exchanges at the interface between land-surface and atmosphere, and dynamical vegetation with different plant functional types (Alessandri 2006; Alessandri et al. 2012).

\subsection{Experiments}

Two different sets of experiments are distinguished: one with the imposition of a reference atmospheric $\mathrm{CO}_{2}$ concentration pathway (hereafter, the PPM family) and one with prescribed negative emissions and the atmospheric $\mathrm{CO}_{2}$ let free to evolve according to the surface fluxes and the general circulation (hereafter, the GTY family). Both PPM and GTY families are idealized experiments that describe the potential effects of a particular CDR policy. The PPM focuses on the concentration in the atmosphere (expressed as ppmv) as an indicator of the policy implementation. It is possible that the world in 2100 will have a global economy that is nearly fully decarbonized but still high $\mathrm{CO}_{2}$ in the atmosphere, and the nations of the

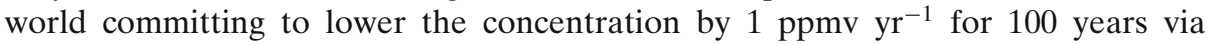
CDR strategies. The issue that can be considered is what removal effort would be required to compensate for ocean outgassing, in addition to the planned removal effort required if outgassing did not exist (about $2.1 \mathrm{Gt} \mathrm{C} \mathrm{yr}^{-1}, 1 \mathrm{ppmv}=2.124 \mathrm{Gt}$ C). We can also imagine a world in 2050 that, even though there are still significant emissions, decides to remove a constant $2.1 \mathrm{Gt} \mathrm{C} \mathrm{yr}^{-1}$ for the following 100 years via CDR strategies. This policy concentrates on establishing a fixed removal rate for atmospheric carbon and since it uses the emission rate as the reference indicator, it will be called a GTY (Gt/Year) policy.

We tested the response of the natural ocean carbon cycle to these policies in two already existing simulations: an adjusted present-climate simulation described in Patara et al. (2011, named CTRL here), where the land component is not considered and the atmospheric $\mathrm{CO}_{2}$ concentration is fixed to $348 \mathrm{ppmv}$, and a transient simulation with the full ESM configuration (see Vichi et al. 2011, for full details), with prescribed observed $\mathrm{CO}_{2}$ until year 2000 and SRES A1B pathways thereafter (Nakicenovic and Swart 2000).

All experiments prescribe a reference removal of atmospheric $\mathrm{CO}_{2}$ down to the pre-industrial concentration of $285 \mathrm{ppmv}$ (a reduction of $63 \mathrm{ppmv}$ equivalent to about 134 Gt C), with different kind of negative emissions as described in Table 1. Prescribed negative emissions are applied with three different time intervals: a 
Table 1 List of the CDR experiments

\begin{tabular}{lllll}
\hline Name & CDR type & Description & $\begin{array}{l}\text { Initial } \\
\text { condition }\end{array}$ & $\begin{array}{c}\text { INE } \\
{[\mathrm{GtC}]}\end{array}$ \\
\hline PPM-0 & $\begin{array}{l}\text { One-time removal } \\
\text { PPM-10 } \\
\text { Linear removal over } \\
\text { 10 years } \\
\text { Linear removal over } \\
\text { PPM-30 years }\end{array}$ & $\begin{array}{c}\text { Prescribed } \mathrm{CO}_{2} \text { pathway } \\
\text { Prescribed } \mathrm{CO}_{2} \text { pathway }\end{array}$ & $\begin{array}{l}\text { CTRL } \\
\text { CTRL }\end{array}$ & -43 \\
GTY-0 & One-time removal & $\begin{array}{c}\text { Instantaneous negative emissions } \mathrm{CO}_{2} \text { pathway } \\
\text { and } \mathrm{CO}_{2} \text { is free to evolve }\end{array}$ & CTRL & -18 \\
GTY-10 & $\begin{array}{c}\text { Linear removal over } \\
\text { Constant negative emissions } \\
\text { and } \mathrm{CO}_{2} \text { is free to evolve }\end{array}$ & CTRL & -26 \\
GTY-30 & $\begin{array}{c}\text { Linear removal over } \\
\text { Constant negative emissions } \\
\text { and } \mathrm{CO}_{2} \text { is free to evolve }\end{array}$ & CTRL & -26 \\
PPM-0T & $\begin{array}{c}\text { One-time removal } \\
\text { As PPM-0 but using the } \\
\text { full ESM configuration }\end{array}$ & TR20 (1988) & -8 \\
PPM-0S & One-time removal & $\begin{array}{c}\text { As PPM-0 but using the } \\
\text { full ESM configuration }\end{array}$ & SA1B (2020) & -49 \\
\hline
\end{tabular}

The CTRL experiment is a 400 year-long present climate simulation with interactive oceanatmosphere (Patara et al. 2011); TR20 and SA1B are transient simulations with observed and scenario greenhouse gases, respectively, using the full ESM configuration (Vichi et al. 2011). The last column reports the Implied Negative Emissions (INE, Section 3.2 and Fig. 2) for each experiment over a 30 years period

reference experiment with one-time instantaneous removal and two with constant removal rates over a period of 10 and 30 years (all homogeneously distributed over the Earth surface). To simplify the comparison, all CDR actions are assumed to occur at a reference year 0 and the years before the CDR are negative. For the transient simulation (PPM-OT in Table 1), an absolute time axis is used, and year 0 corresponds to 1988 when the prescribed concentration was $348 \mathrm{ppmv}$ as used in the present-climate CTRL experiment. The CDR in the scenario simulation (PPMOS in Table 1) is supposed to occur at year 2020. Only carbon dioxide is removed and all other greenhouse gases are maintained constant or as observed for the rest of the 20th century and follow the A1B scenario for the part of the simulation extending into the 21st century (Vichi et al. 2011). As the adjustment to the negative emissions occurs in about 20 years in most cases, the simulations are continued for 30 years after the end of the CDR actions.

\section{Results}

3.1 Atmospheric $\mathrm{CO}_{2}$ and the ocean carbon flux

The PPM-0 family of experiments in Table 1 assumes that the policy target is the atmospheric concentration and that negative emissions have to be continuously adjusted to maintain the prescribed concentration. In the extremely idealized PPM0 case, this implies an initial instantaneous removal of $134 \mathrm{Gt} \mathrm{C}$ to force the drop down to the preindustrial level and the subsequent maintenance rate depends on the natural mobilization of anthropogenic carbon stored in the ocean. The equivalent experiment in the GTY-0 family differs in the absence of deliberate maintenance 
after the CDR. Figure 1 shows the departure of GTY-0 from the target $\mathrm{CO}_{2}$ value of PPM-0 after the sudden removal, when the CDR measures have ceased. A resulting value of about $298 \mathrm{ppm}$ is attained after $10-15$ years, which is 13 ppm higher than the preindustrial target.

Experiment GTY-10 shows that a constant rate of negative emissions (calibrated to remove the 63 ppmv from the atmosphere in 10 years) does not attain the target value in the desired time frame (Fig. 1). The concentration at the end of the CDR action is about $6 \mathrm{ppm}$ higher and it further increases to about the same value of GTY-0 in the next 20 years. The target value is instead almost attained when negative emissions are distributed over 30 years as in GTY-30 and the resulting atmospheric $\mathrm{CO}_{2}$ is always close (and initially below) the theoretical target. The rebound effect is also reduced and the adjustment concentration is 5 ppmv higher than the preindustrial value.

Figure 2 presents the resulting carbon fluxes between the oceanic pool and the atmosphere for 30 years after the beginning of the CDR actions. In the case of the one-time removal of carbon dioxide at year 0 (PPM-0, Fig. 2a), there is a sudden release of inorganic carbon from the ocean that returns to neutral flux values in less than 30 years as previously reported by Cao and Caldeira (2010) using an intermediate complexity model. The imposition of a linear $\mathrm{CO}_{2}$ decrease (PPM-10 and PPM30, Table 1) removes the initial shock and therefore reduces the total ocean carbon release of the CDR as reported in the figure legend (see also Section 3.2 below). However, the adjustment depends on the reference pathway, since PPM-30 leads to an increase to positive values of the ocean outgassing instead of an adjustment to near zero over the target 30 years period. The one-time removal GTY-0 experiment with free-evolving atmospheric concentration leads to a quicker adjustment of the carbon exchange flux than PPM-0 (Fig. 2b). This is a clear consequence of relaxing the prescription of a reference $\mathrm{CO}_{2}$ pathway and therefore the atmosphere-ocean system finds a new atmospheric concentration value (Fig. 1) which is in equilibrium with a slightly higher ocean $\mathrm{pCO}_{2}$ (not shown). The adjustment of the air-sea carbon flux is attained in about the same period when prescribing constant negative emissions

Fig. 1 Time series of the atmospheric $\mathrm{CO}_{2}$ concentration during the Carbon Dioxide Removal (CDR) experiments (Table 1) and for 20 years after the end of the removal action

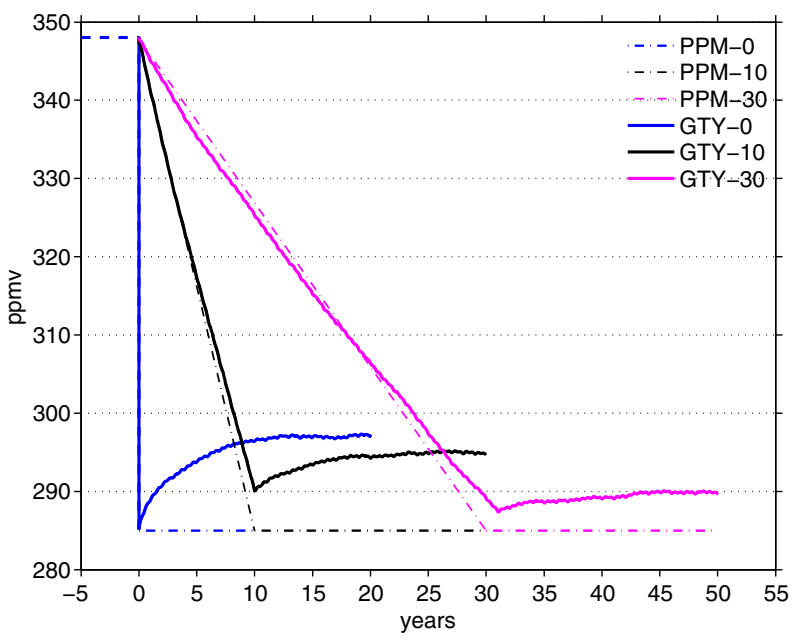


Fig. 2 Mean annual carbon flux integrated over the global ocean (positive upward) for a the PPM family of experiments and $\mathbf{b}$ the GTY experiments with free evolving atmospheric $\mathrm{CO}_{2}$ (Table 1). The numbers in brackets in the legends are the (negative) implied emissions computed by integrating the curves over the years 0-30 (a)

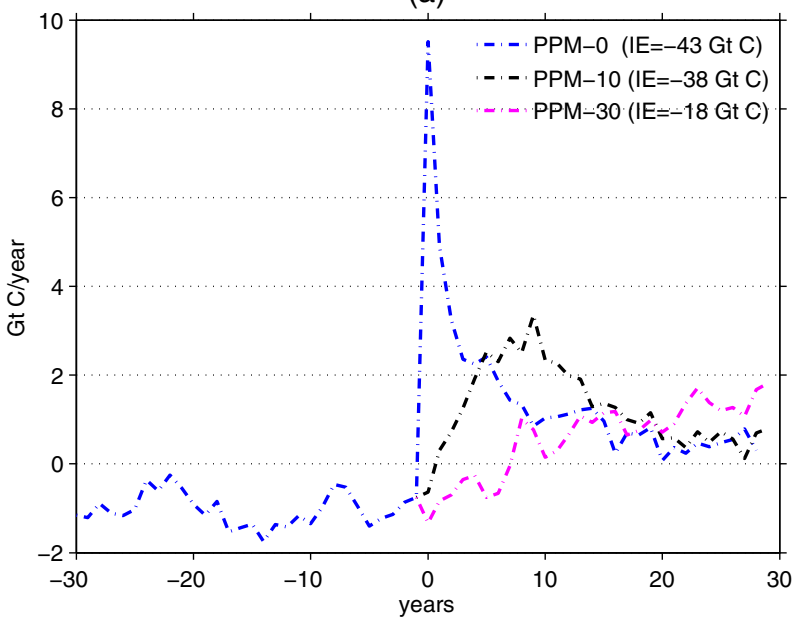

(b)

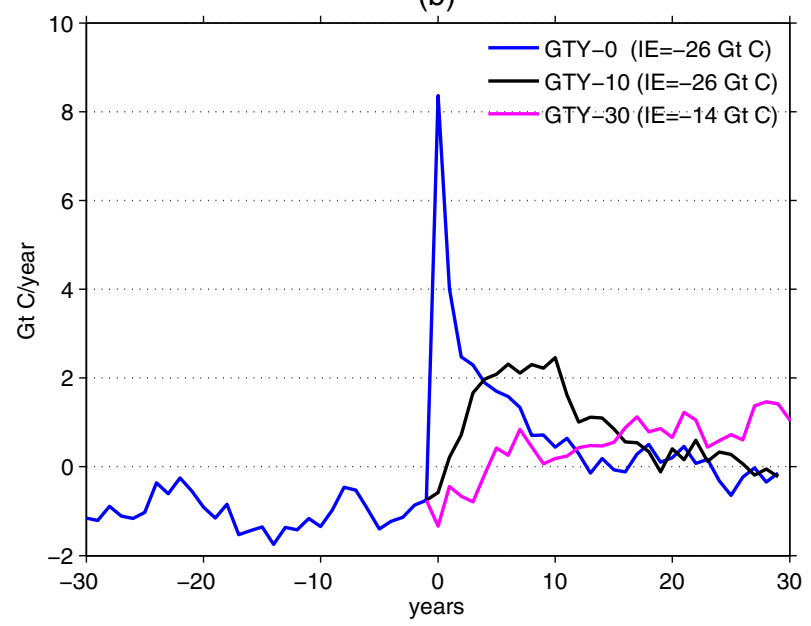

over 10 years as done in GTY-10. GTY-30 is similar to PPM-30, both showing that at the end of the longer-term CDR action the ocean is still a source of anthropogenic carbon to the atmosphere because of the slower adjustment outgassing rates of the ocean that will be further studied in Section 3.3.

\subsection{Implied negative emissions}

The concept of implied emissions is proposed here to measure the overall carbon removal effort. This concept was introduced by Hibbard et al. (2007) and applied by Johns et al. (2011) to reconstruct the role of natural carbon sinks in the maintenance of stabilized concentration pathways. Implied emissions are defined as the sum of the fluxes with the terrestrial and oceanic components and in our case are simply the integral of the ocean carbon flux shown in Fig. 2 with the opposite sign. The 
implied emissions are almost always negative during a CDR policy (Implied Negative Emissions, INE), since the target $\mathrm{CO}_{2}$ level is much lower than the initial control value.

The PPM experiments would necessarily require substantially higher INE than the planned removal of $134 \mathrm{Gt} \mathrm{C}$, since 43, 38 and $18 \mathrm{Gt}$ of ocean anthropogenic carbon have to be additionally removed from the atmosphere in a 30 years period for PPM-0, PPM-10 and PPM-30, respectively (Fig. 2a and Table 1). On the other hand, less ocean carbon (26 Gt C) would be released into the atmosphere for both the GTY-0 and GTY-10 experiments, which corresponds to the observed increase of about 12 ppm (Fig. 1), and even less for GTY-30 over the considered period (Fig. 2b and Table 1).

The INE time series represent the additional effort of the policy that has to be undertaken in addition to the planned $134 \mathrm{Gt} \mathrm{C} \mathrm{CDR} \mathrm{because} \mathrm{of} \mathrm{the} \mathrm{natural} \mathrm{ocean}$ outgassing. We have examined it more in detail in Fig. 3 for the GTY experiments with distributed CDR. The extra work increases quite quickly in GTY-10 during the CDR period, requiring an additional carbon removal comparable to the estimation of the oceanic sink in CTRL which remains rather high also for the next 20 years after the end of the CDR. This effort is reduced on a yearly basis for GTY-30 because at the beginning the ocean is still anticipated to act a sink and the slower CDR rate allows a better adjustment that reduces the outgassing. In both cases the INE are close to 0 after 30 years from the end of the CDR actions (as it occurs for the PPM experiments, not shown), although the ocean is not anymore a sink as during the CTRL experiment (Fig. 2b).

\subsection{Ocean regional responses}

The response of the ocean to changes in atmospheric $\mathrm{CO}_{2}$ is not homogeneous (Crueger et al. 2008; Vichi et al. 2011). This is due to differences in ocean dynamics (such as the ventilation of deeper waters), the pre-formed distribution of carbonate variables (e.g. Key et al. 2004) and the intensity of biological processes.

Fig. 3 Time series of the implied negative emissions (INE) (continuous lines) shown on top of the planned removal effort (dashed lines) for GTY-10 and GTY-30 and presented for 20 years after the end of the CDR measures

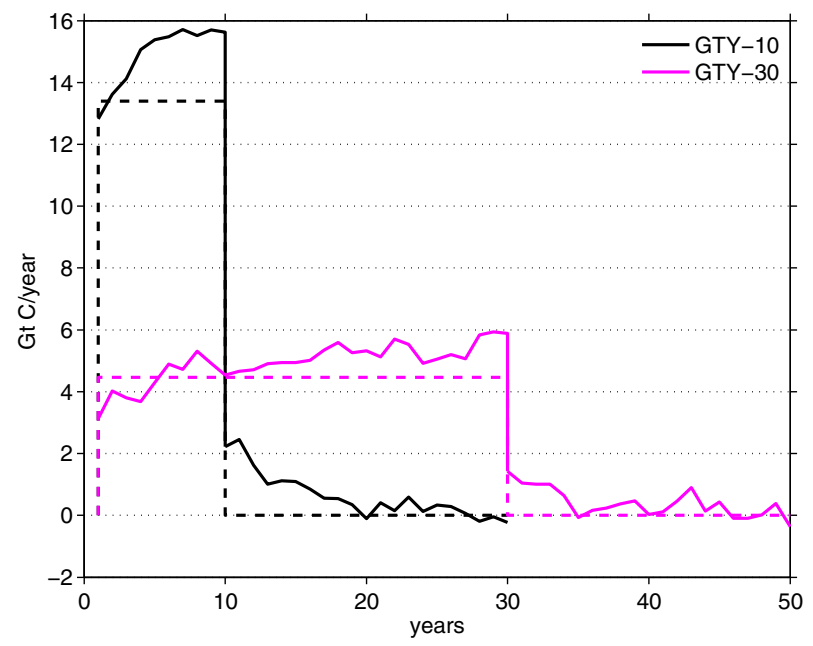


Figure 4 presents the maps of annual mean carbon fluxes from the ocean to the atmosphere in the CTRL simulation compared with the annual means from the GTY-0 experiment in the first year after the sudden removal and the average of

(a)

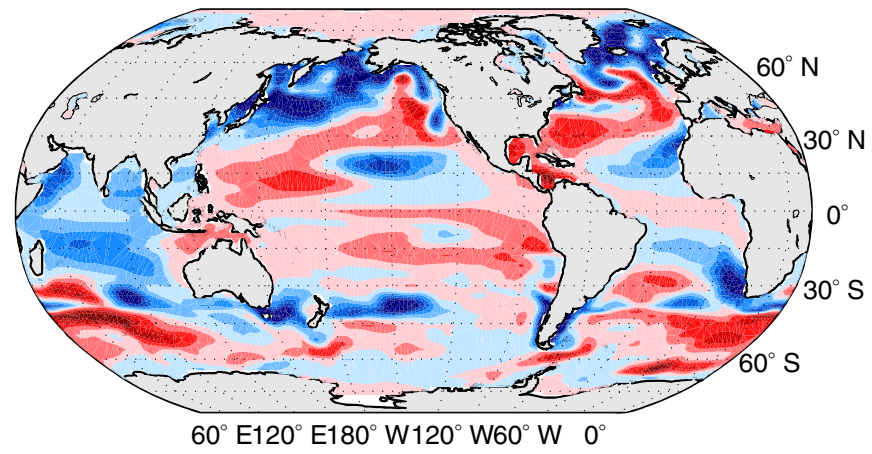

(b)

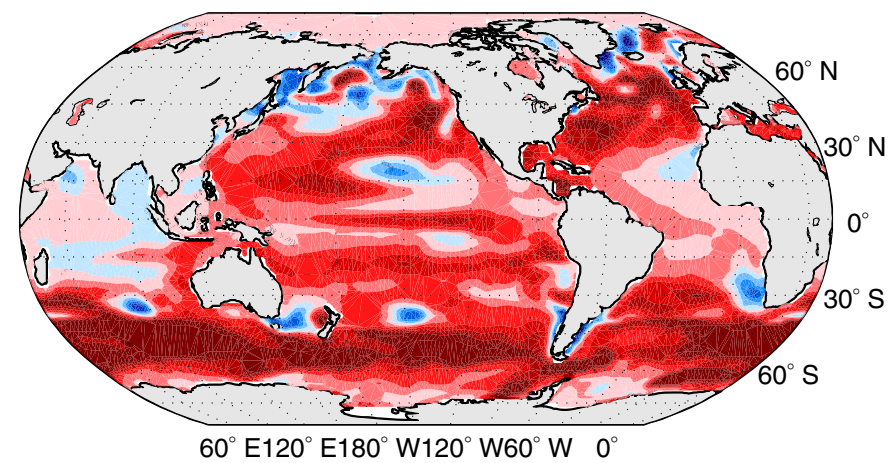

(c)

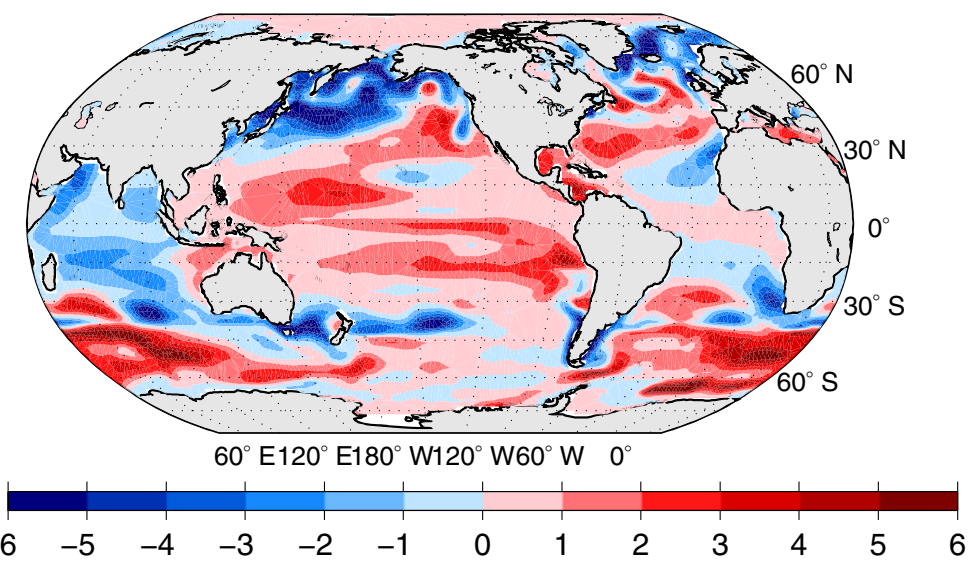

Fig. 4 Mean annual carbon fluxes between ocean and atmosphere (positive upward) in mol $\mathrm{C} \mathrm{m}^{-2}$ $\mathrm{yr}^{-1}$ from GTY-0 computed over a 10 years of CTRL right before the CDR; b year 1 after the removal; $\mathbf{c}$ average over the period 20-30 years after the CDR 
the last 10 years. The outgassing is rather homogeneously distributed over the entire ocean right after the one-time CDR (Fig. 4b), with larger values in the Southern Ocean and North Atlantic and lower in the Indian Ocean and equatorial Atlantic. At the end of the 30 years all ocean basins return to similar values as during the control (Fig. 4c), apart from the Southern Ocean (SO, especially the Indian and Atlantic sectors) and the equatorial Pacific to a lesser extent. This in an indication that the anthropogenic carbon is mostly stored in the upper ocean where the removal can be achieved in a time period of 30 years and that the SO is the key player in the regulation of the ocean-atmosphere fluxes.

To better investigate the adjustment time scales of the different oceans, we have computed the mean fluxes for each basin, both integrated over the surface and as average values from the GTY-0 experiment (Fig. 5). An exponential fit was used to evaluate the decay time scales (avoiding the initial abrupt decay and both for the total and the surface-averaged carbon fluxes). After the removal, the largest outgassing

Fig. 5 Regional ocean fluxes from the GTY-0 experiment. The Southern Ocean (SO) is defined as the region below $50^{\circ} \mathrm{S}$. The dashed lines are the exponential fits with the decay constant values indicated in the legend (a)

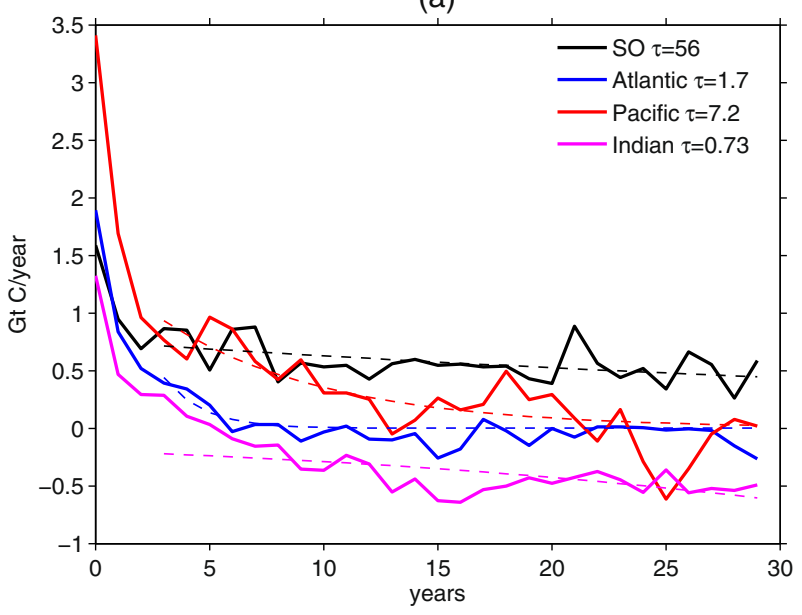

(b)

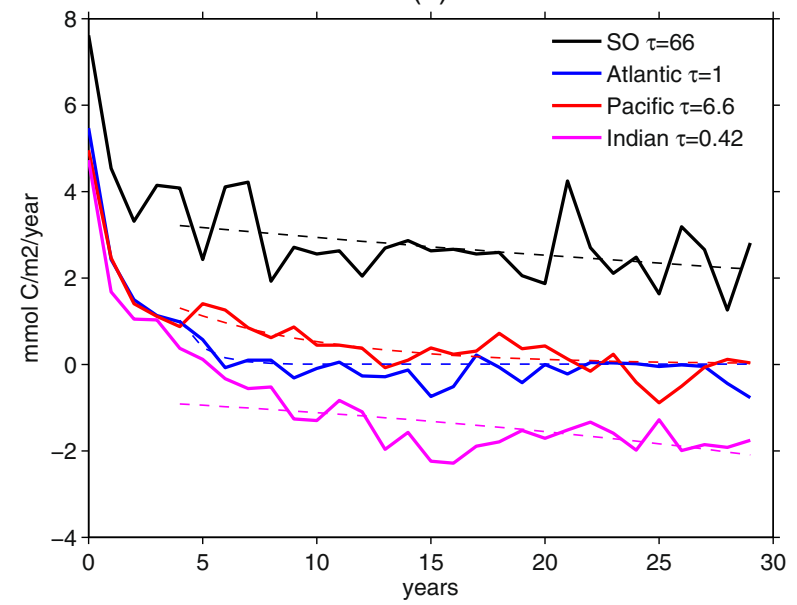


is observed in the Pacific Ocean that dominates because of the largest dimensions, while the SO has the largest contribution in terms of flux intensity (Fig. 5b). After about 15 years, the carbon release from the Pacific Ocean is close to 0 , and the SO becomes the only carbon source to the atmosphere. Not all regions are expected to reach equilibrium with the atmosphere as other mechanisms linked to the biological carbon pumps are at play (Crueger et al. 2008; Vichi et al. 2011). According to the exponential fit coefficients, the Indian Ocean has the shorter adjustment time scale, although this ocean is biased in these simulation results as it behaves as a carbon sink instead of a source (Vichi et al. 2011). The Atlantic and the Pacific oceans show longer time scales with adjustment periods of 1-10 years. The SO is the basin that provides the slowest time scales of carbon exchange with the atmosphere with adjustment times of order 50 years.

\subsection{Transient and scenario simulations}

The results presented above have been obtained with a model considering only the ocean-atmosphere portion of the natural carbon cycle and under constant $\mathrm{CO}_{2}$ concentration representative of the 20th century climate. This was specifically done to reduce the uncertainties on the climate system response and the terrestrial fluxes that are considerably less constrained (e.g. Friedlingstein et al. 2006). This section shows results from a simulation with the full ESM under the prescription of transient and scenario $\mathrm{CO}_{2}$ pathways (PPM-OT and PPM-0S, Table 1), which implies that both the ocean and the land system do not modify the atmospheric carbon concentration and do not influence each other.

The comparison between these experiments and the reference PPM- 0 is presented in Fig. 6. The one-time removal in PPM-0T was prescribed when the atmospheric concentration is equal to the one used in PPM-0 (year 1988), but the differences in the simulation setup led to a different background state of the initial ocean carbon flux, which is a larger sink in PPM-0T than in PPM-0. The ocean responds differently to the transient simulation with a somewhat larger sink, also because it is characterized by a colder mean state (Vichi et al. 2011). The change of carbon flux from the

Fig. 6 Comparison of the mean annual carbon flux integrated over the global ocean (positive upward) between the transient/scenario simulations and PPM-0. Total carbon flux toward land and ocean is superimposed for PPM-0T. An absolute time scale is used here to highlight that an historical and scenario simulations are done and year 1988 corresponds to year 0 in the previous figures

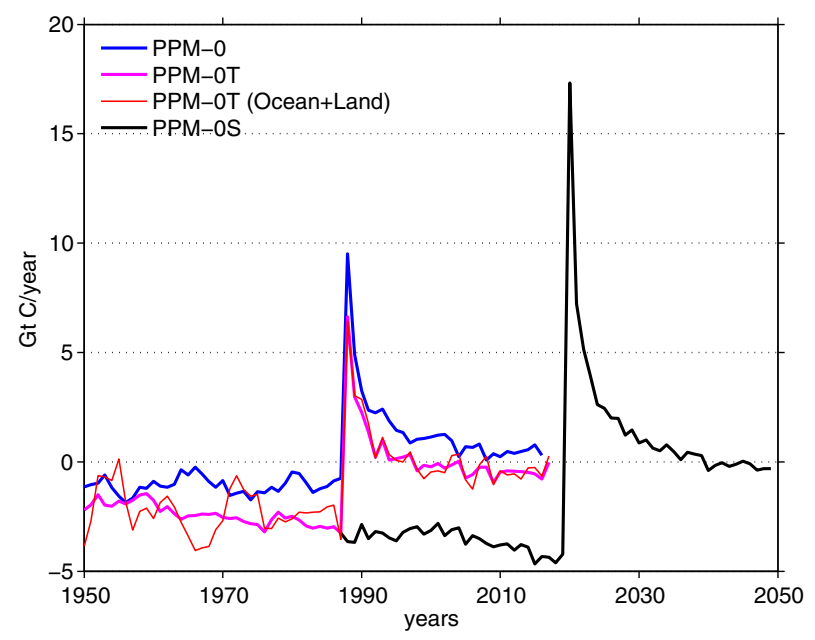


ocean is equivalent (as this is a function of the accumulated anthropogenic carbon), but the adjustment to the neutral surface flux is quicker in PPM-0T and this leads to a considerably lower INE (Table 1 ) indicating a sensitivity of this value to the initial ocean state. The addition of the land flux (thin red line in Fig. 6) shows that before the CDR the total carbon uptake is strongly modulated by land processes, while in this specific ESM simulation the contribution of the terrestrial carbon flux is much smaller after the CDR (see Section 4 for a discussion). On the other hand, the scenario simulation PPM-OS shows that the oceanic release of anthropogenic carbon is much higher if the CDR action is done with a higher atmospheric $\mathrm{CO}_{2}$ concentration with a INE of $48 \mathrm{Gt} \mathrm{C}$ (Table 1). This trend confirms the results of Cao and Caldeira (2010), who performed one-time CDR experiments at year 2050 and obtained a peak ocean flux of about $25 \mathrm{Gt} \mathrm{C/year.}$

\section{Discussion and conclusions}

The prescribed one-time removal of 63 ppmv (134 Gt C) is clearly a mathematical exercise given the current state of technical knowledge. To put this number into perspective, it is equivalent to the estimated annual rate of terrestrial gross primary production or about 2-3 times the ocean net primary production (Falkowski et al. 2000). Distributing this number over a period of 10 and 30 years would require a set of policies with negative emission rates of 13 and $4.5 \mathrm{Gt} \mathrm{C} \mathrm{yr}^{-1}$, which are respectively about $70 \%$ more and $50 \%$ less than the current anthropogenic emissions (Friedlingstein et al. 2010). The removal rate of $4.5 \mathrm{Gt} \mathrm{C} \mathrm{yr}^{-1}$ for 30 years is probably as fast as any credible CDR can be and it is of extreme interest to policymakers to assess whether there would be any additional required effort due to the response of the natural carbon cycle to the CDR action.

The results presented here have investigated two possible families of CDR policies: prescribed target pathways (PPM) and prescribed negative $\mathrm{CO}_{2}$ emissions (GTY). Both PPM and GTY families are likely to release substantial amounts of anthropogenic carbon from the ocean for about 20 years after the end of the action. There is however a clear difference in the implied negative emissions associated to each action; the extra work in the GTY action is smaller than PPM because the resulting time scales of air-sea $\mathrm{CO}_{2}$ exchange are more comparable with the buffering rates of the natural ocean carbon cycle. This may be understood by looking at Fig. 3: at the beginning of the CDR in GTY-30, the ocean still acts as a sink that further helps to absorb the excess atmospheric $\mathrm{CO}_{2}$, while a more marked removal induces a change in the surface carbonate system equilibrium leading to outgassing.

Our results have been obtained with a simplified set-up (Section 2.2) and the pair of initial and target $\mathrm{CO}_{2}$ values is different from the one that the world will have to deal with when starting any realistic CDR policy. The involved fluxes may thus be different: this is why we added the experiments in Section 3.4, which indicate that the amount of the ocean carbon release may depend on the initial mean oceanic flux, which may also be a function of the mean ocean state. It is also confirmed that performing a CDR with a larger atmospheric concentration (that is waiting for the ocean to store more anthropogenic carbon) would lead to a substantially higher release of carbon in response to the CDR measure (as found in Cao and Caldeira 2010). In summary, the release of carbon from the ocean may be smaller than found 
here if the ocean is a larger sink than currently estimated and it is anticipated to progressively increase if the CDR will start at the end of the century in a higher $\mathrm{CO}_{2}$ world. It may also be hypothesized that also the GTY policy would be less effective, as the surface warming would reduce the exchange rates of carbon.

Most of the idealized experiments have been performed with an oceanatmosphere system because there are direct evidences that anthropogenic carbon has been stored in the ocean. This is clearly an approximation of the full carbon cycle system: the terrestrial part is quicker to react and largely uncertain (at least according to model results, Friedlingstein et al. 2006; Johns et al. 2011), but the response strongly depends on the parameterization of $\mathrm{CO}_{2}$ fertilization in the modelled terrestrial vegetation. Cao and Caldeira (2010) found in their simulations that terrestrial net primary production (NPP) is largely sensitive to the atmospheric removal and this eventually drives soil respiration. A large reduction in NPP is first observed because of the reduced atmospheric $\mathrm{CO}_{2}$ value that stops the fertilization effect, and then a reduction in soil respiration follows because less carbon is transferred to this stock. This implies that only the fluxes due to increased fertilization are modified, and carbon is not mobilized from a previous storage in the terrestrial stocks as instead it occurs for the ocean. The PPM-0T and PPM-0S experiments presented in Section 3.4 shows that the land response to a PPM CDR is much lower than the ocean response if a vegetation model with little fertilization effect is used. It is argued that the response of this land model would be the same in a transient GTY experiment because it is the lowering of the atmospheric concentration that reduces the land response. Given the large spread in land carbon fluxes when considering different ESMs (e.g. Johns et al. 2011), there are still considerable uncertainties in the amount of implied negative emissions that would be derived from the terrestrial component, while the uncertainties for the ocean mostly depends on the value of the current carbon sink.

The computational constraints of using an ESM with detailed dynamics are still high and only a limited set of experiments was performed. Therefore, these results need to be supported by additional simulations with different models and setups, although, within the limits of using one model realization, there are evident advantages of using a CDR policy based on target negative emissions, since it is more compliant with the carbon fluxes at the ocean time scales.

Acknowledgements We gratefully acknowledge the support of Italian Ministry of Education, University and Research and Ministry for Environment, Land and Sea through the project GEMINA. We also wish to thank the anonymous reviewers and the Guest Editors for their comments on an early version of the manuscript.

Open Access This article is distributed under the terms of the Creative Commons Attribution License which permits any use, distribution, and reproduction in any medium, provided the original author(s) and the source are credited.

\section{References}

Alessandri A (2006) Effects of land surface and vegetation processes on the climate simulated by an atmospheric general circulation model. PhD thesis, Bologna University Alma Mater Studiorum 
Alessandri A, Borrelli A, Masina S, Cherchi A, Gualdi S, Navarra A, Di Pietro P, Carril AF (2010) The INGV-CMCC seasonal prediction system: improved ocean initial conditions. Mon Weather Rev 138(7):2930-2952. doi:10.1175/2010MWR3178.1

Alessandri A, Fogli PG, Vichi M, Zeng N (2012) Strengthening of the hydrological cycle in future scenarios: atmospheric energy and water balance perspective. Earth Syst Dynam 3:199-212. doi:10.5194/esd-3-199-2012

Boden T, Marland G, Andres R (2011) Global, regional, and national fossil-fuel co2 emissions. Tech. rep., Carbon Dioxide Information Analysis Center, Oak Ridge National Laboratory, U.S. Department of Energy, Oak Ridge, Tenn., USA. http://cdiac.ornl.gov/trends/emis/tre_usa.html. Accessed 19 Feb 2013

Cao L, Caldeira K (2010) Atmospheric carbon dioxide removal: long-term consequences and commitment. Environ Res Lett 5(2). doi:10.1088/1748-9326/5/2/024011

Crueger T, Roeckner E, Raddatz T, Schnur R, Wetzel P (2008) Ocean dynamics determine the response of oceanic co2 uptake to climate change. Clim Dyn 31(2-3):151-168. doi:10.1007/s00382007-0342-x

Etkin B (2010) A state space view of the ice ages - a new look at familiar data. Clim Change 100:403406. doi:10.1007/s10584-010-9821-x

Falkowski P, Scholes R, Boyle E, Canadell J, Canfield D, Elser J, Gruber N, Hibbard K, Högberg P, Linder S, Mackenzie F, III BM, Pedersen T, Rosenthal Y, Seitzinger S, Smetacek V, Steffen W (2000) The global carbon cycle: a test of our knowledge of Earth as a system. Science 290:291-296

Fogli PG, Manzini E, Vichi M, Alessandri ALP, Gualdi S, Scoccimarro E, Masina S, Navarra A (2009) INGV-CMCC Carbon: a carbon cycle earth system model. Tech. Rep. RP0061, CMCC. URL http://www.cmcc.it/publications-meetings/publications/research-papers/rp0061-ingv-cmcccarbon-icc-a-carbon-cycle-earth-system-model

Friedlingstein P, Cox P, Betts R, Bopp L, Von Bloh W, Brovkin V, Cadule P, Doney S, Eby M, Fung I, Bala G, John J, Jones C, Joos F, Kato T, Kawamiya M, Knorr W, Lindsay K, Matthews HD, Raddatz T, Rayner P, Reick C, Roeckner E, Schnitzler KG, Schnur R, Strassmann K, Weaver AJ, Yoshikawa C, Zeng N (2006) Climate-carbon cycle feedback analysis: Results from the c4mip model intercomparison. J Climate 19(14):3337-3353

Friedlingstein P, Houghton RA, Marland G, Hackler J, Boden TA, Conway TJ, Canadell JG, Raupach MR, Ciais P, Le Quere C (2010) Update on CO2 emissions. Nature Geosci 3(12):811812. doi:10.1038/ngeo1022

Gruber N, Gloor M, Mikaloff Fletcher SE, Doney SC, Dutkiewicz S, Follows MJ, Gerber M, Jacobson AR, Joos F, Lindsay K, Menemenlis D, Mouchet A, Mueller SA, Sarmiento JL, Takahashi T (2009) Oceanic sources, sinks, and transport of atmospheric CO2. Glob Biogeochem Cycles 23:GB1005. doi:10.1029/2008GB003349

Gualdi S, Scoccimarro E, Navarra A (2008) Changes in tropical cyclone activity due to global warming: results from a high-resolution coupled general circulation model. J Climate 21(20):5204-5228

Hibbard K, Meehl G, Cox P, Friedlingstein P (2007) A strategy for climate change stabilization experiments. EOS 88(20):217. doi:10.1029/2007EO200002

Johns T, Royer JF, Höschel I, Huebener H, Roeckner E, Manzini E, May W, Dufresne JL, Otterå O, van Vuuren D, Salas y Melia D, Giorgetta M, Denvil S, Yang S, Fogli P, Körper J, Tjiputra J, Stehfest E, Hewitt C (2011) Climate change under aggressive mitigation: the ensembles multimodel experiment. Clim Dyn 1-29. doi:10.1007/s00382-011-1005-5

Keith DW (2009) Why capture $\mathrm{CO}_{2}$ from the atmosphere? Science 325(5948):1654-1655. doi:10.1126/science.1175680. URL http://www.sciencemag.org/content/325/5948/1654

Key RM, Kozyr A, Sabine CL, Lee K, Wanninkhof R, Bullister JL, Feely RA, Millero FJ, Mordy C, Peng TH (2004) A global ocean carbon climatology: results from global data analysis project (GLODAP). Glob Biogeochem Cycles 18(4):GB4031

Le Quéré C, Raupach M, Canadell J, Marland G, et al (2009) Trends in the sources and sinks of carbon dioxide. Nature Geosci 2:831-836

Matthews HD, Gillett NP, Stott PA, Zickfeld K (2009) The proportionality of global warming to cumulative carbon emissions. Nature 459(7248):829-832. doi:10.1038/nature08047

Nakicenovic N, Swart R (eds) (2000) Special report on emissions scenarios. A special report of working group III of the Intergovernmental Panel on Climate Change. Cambridge University Press, Cambridge. ISBN 0521804930

Navarra A, Kinter JL, Tribbia J (2010) Crucial experiments in climate science. Bull Am Meteorol Soc 91(3):343-352. doi:10.1175/2009BAMS2712.1 
Patara L, Visbeck M, Masina S, Krahmann G, Vichi M (2011) Marine biogeochemical responses to the north atlantic oscillation in a coupled climate model. J Geophys Res 116(C7). doi:10.1029/2010JC006785

Solomon S, Plattner GK, Knutti R, Friedlingstein P (2009) Irreversible climate change due to carbon dioxide emissions. Proc Natl Acad Sci 106(6):1704-1709. doi:10.1073/pnas.0812721106. URL http://www.pnas.org/content/106/6/1704.abstract

Trenberth K, Jones P, Ambenje P, Bojariu R, Easterling D, Tank AK, Parker D, Rahimzadeh F, Renwick J, Rusticucci M, Soden B, Zhai P (2007) Observations: surface and atmospheric climate change. In: Solomon S, Qin D, Manning M, Chen Z, Marquis M, Averyt K, Tignor M, Miller H (eds) Climate change 2007: the physical science basis. Contribution of working group I to the fourth assessment report of the Intergovernmental Panel on Climate Change. Cambridge University Press, Cambridge/New York

Vichi M, Masina S (2009) Skill assessment of the PELAGOS global ocean biogeochemistry model over the period 1980-2000. Biogeosciences 6(11):2333-2353. URL http://www. biogeosciences.net/6/2333/2009/

Vichi M, Pinardi N, Masina S (2007) A generalized model of pelagic biogeochemistry for the global ocean ecosystem. Part I: theory. J Mar Syst 64:89-109

Vichi M, Manzini E, Fogli P, Alessandri A, Patara L, Scoccimarro E, Masina S, Navarra A (2011) Global and regional ocean carbon uptake and climate change: sensitivity to a substantial mitigation scenario. Clim Dyn 37(9):1929-1947. doi:10.1007/s00382-011-1079-0 